\title{
4. Anthropology of regulation
}

\section{INTRODUCTION}

Chapters 2 and 3 provided a conceptual framework and historical regulatory tracing of RECs, arguing that the roles and practices of RECs may be shifting in response to next-generation health research regulation. I showed how the previous generation of regulatory design, which was notably marked by self-regulation of health research involving participants-that is, ad hoc ethics peer review largely conducted by fellow scientists based on local customs and guidance from the medical profession (and the RCP especially) — gradually gave way to stricter, stronger, more centralized forms of regulation, particularly through statutes and policies set by the government. This was done to provide better coordination and coherence for researchers, research sponsors, and publics, in large part as a response to years of criticism that generated a crisis of reputational risk to RECs, threatening their legitimacy. This was also done by necessity in response to developments in EU law, such as the Clinical Trials Directive 2001.

This chapter situates the conceptual framework and the historical tracing in the present context by sketching the possible regulatory techniques and behaviours employed by RECs and their managing regulators. Subsequent chapters will consider the empirical question of whether, and, if so, how these regulatory techniques and behaviours appear in practice. Here, I explain the research approach, theoretical underpinnings, and analytical concepts that drive my empirical research.

To make sense of my empirical data, I employ the method of thematic analysis (explained below), which is informed by 'sensitizing concepts' 1 drawn from regulatory theory and anthropology. Specifically, I explore regulatory theory, design, and strategy, focusing on the concepts of 'regulatory space', 'proportionate regulation', and 'risk-based regulatory approach'. These sensitizing concepts add further analytic weight to the

1 A sensitizing concept is an interpretive device for a qualitative study that informs the overall research problem. See Glenn Bowen, 'Grounded Theory and Sensitizing Concepts’ (2006) 5 International Journal of Qualitative Methods 1. 
historical tracing undertaken in Chapter 3. They also allow us to better understand the precise regulatory form and functions of RECs, as well as the regulatory strategies employed by RECs and other regulators of health research, which will be discussed in subsequent chapters.

The central question that will emerge from the theoretical discussion in this chapter is: what do the empirical research findings tell us about the nature of the interaction between central regulators (foremost the HRA) and RECs, and the functional operations and deliberative processes of RECs in an era of twinned regulatory objectives of participant protection and research promotion? Another central question that will emerge is: do the empirical research findings reflect and validate the suggestions supplied in Chapters 2 and 3 that RECs engage in risk-based regulation, and that health research regulation is increasingly streamlined and proportionate? In other words, are RECs really risk-based, proportionality-attuned regulators, or is something else going on, and if so, what? What might proportionate and 'streamlined' regulation mean?

I will argue in this chapter that the main approaches to investigating law empirically (e.g. legal anthropology, socio-legal studies) should be supplemented to adequately answer my research questions as these approaches are commonly designed to understand law and legal practice rather than regulation and regulatory practice-fields that I have endeavoured to show are ontologically distinct. I explain the justification for going beyond them and harnessing a novel methodological approach that I call an 'anthropology of regulation', which structures my overall empirical enquiry. I claim that this is a methodological supplement to existing anthropological and socio-legal research approaches. As anthropology of regulation draws explicit attention to processes, passages, and change, I further draw on the anthropological concept of liminality. Liminality thus also serves as a sensitizing concept, in addition to those concepts provided by regulatory theory. Together with regulatory theory, liminality helps us to better understand the nature of transformations of actors within the regulatory space, the form of regulation in this space, as well as the behaviours and experiences of actors as they go through processes of change. In short, anthropology of regulation as an approach and field of enquiry adds explanatory power to my empirical data and to the kinds of contributions that socio-legal work might also make.

Thus, the key aim of this chapter is to explain and justify my research approach. I do this in several steps. First, I show how regulatory theory provides a solid but ultimately insufficient foundation on its own for the empirical investigation. Second, I explain that there is a need for an empirically grounded discussion of regulatory practice, but that extant socio-legal and legal anthropology approaches need to be supplemented 
to address fully the research questions. Therefore, I propose an anthropology of regulation that blends the theoretical with the empirical, and which affords a methodological contribution to the fields of socio-legal studies and legal anthropology, in part by drawing attention to (regulatory) processes and change, which was illustrated in the conceptual framework and historical tracing in the previous chapters. I argue that this approach, underpinned by regulatory theory and liminality, serves as a robust platform for making sense of the empirical data, as well as setting those data in a more meaningful context relative to the historical account. It offers a richer account of the steady, incremental transitions in health research regulatory practice across time. It also offers new ways of imagining the regulatory framework for ethics review of health research, namely through regulatory stewardship, and of understanding how liminality provides a powerful, unique, and useful heuristic for making sense of how RECs navigate participant protection and research promotion in an era of next-generation health research regulation.

\section{REGULATORY THEORY}

Regulatory theory is defined as 'a set of propositions or hypotheses about why regulation emerges, which actors contribute to that emergence and typical patterns of interaction between regulatory actors'. ${ }^{2}$ Regulatory theory serves as an important underpinning because it helps provide an explanation for what is going on.

RECs are regulators of health research in that they quite clearly serve as social controls of science. They are 'independent' bodies charged with assessing the ethical acceptability of health research proposals, and thereby determine whether the project should be undertaken. Since their establishment, RECs have been delegated authority from the government and regulatory agencies to determine, often through norms of practice set by the medical and science professions, the ethical acceptability of a research project. On a case-by-case basis, RECs set the conditions around how a given project should be conducted. Always, their independence from both managing regulatory authorities and other organizations (be it NHS Trusts or Health Boards, or otherwise) is emphasized.

While RECs regulate the activities of researchers, above them sits a RES (not always named such) in each of the four nations that regulate the RECs' activities. Each RES is itself situated within a regulatory authority

2 Bronwen Morgan and Karen Yeung, An Introduction to Law and Regulation: Text and Materials (CUP 2007) 16. 
(e.g. CSO in Scotland, HRA in England) that issues sets of commands to be applied by the RES, and through them, RECs, within their respective but coordinated jurisdictions. The HRA is the primary authority for RECs in England but cooperates with equivalent authorities in the three other nations in the exercise of their respective functions relating to the regulation of assessments of the ethics of health and social care research, with a view to coordinating and standardizing practice in the UK relating to such regulation. ${ }^{3}$ Thus, in many ways, the HRA is the UK's primary health research authority with regulatory command of RECs (primes inter pares) as seen through its control of regulatory instruments such as the REC SOPs, GAfREC, and the UK Policy Framework.

The ethnographic work of Neil Stephens and colleagues at the UK Stem Cell Bank ${ }^{4}$ suggests, however, that even if a (meta- or managing) regulator has ultimate legal authority, it may not necessarily have day-to-day authority. Stephens and colleagues found that despite what formal regulations mandate regarding the quality and origins of the stem cell lines received from depositors, scientists engage in a kind of interpretive flexibility when it comes to interpreting and operationalizing the regulations. Scientists at the UK Stem Cell Bank engage in 'bridging strategies' to reconcile the written demands of regulators and the social demands of scientific practice. Efforts to resolve tensions in the practical implementation of regulatory guidance are done through 'instantiated regulation', which describes the processes of translating written regulatory guidance into practical action ('making the documented doable'), and which serves as 'a response to the interpretative flexibility of regulatory texts'. 5 For Stephens and colleagues, regulatory instantiation demonstrates the inherent interpretive and procedural flexibility of regulatory scripts and demonstrates that regulation is always distributed and locally managed by the actors on the ground. In the case of the UK Stem Cell Bank, regulatory instantiation was demonstrated in the (1) iterative modification of the Cell Line Information Form by the UK Stem Cell Bank working together with laboratories; (2) visits to the laboratories by the UK Stem Cell Bank, which built trust through networks; and (3) the shaping of both laboratory and UK Stem Cell Bank practices as a result of these interactions.

3 Care Act 2014, s 111(4).

4 Neil Stephens and others, 'Documenting the Doable and Doing the Documented: Bridging Strategies at the UK Stem Cell Bank' (2011) 41 Social Studies of Science 791 .

5 ibid 794. 
The insight from Stephens and colleagues ties in with the discussion of the interstitial nature of many regulatory spaces within a formal regulated space. Their insight suggests that as both regulators and regulatees, RECs, too, must navigate situationally specific ways to implement regulations (from the SOPs, GAfREC, and so on) that govern their practice in determining the ethical acceptability of research proposals. It also further suggests that RECs may have more regulatory flexibility than we may think and that part of this flexibility is based on 'interpersonal trust in instantiating and maintaining system trust' ${ }^{6}$ In the following chapters, insights from Stephens and colleagues will be invoked in discussions surrounding the key theme of 'regulatory stewardship' and its connection with liminality.

Describing the nested regulatory structure of RECs and opportunities for instantiated regulation is distinct from exploring why ethics review regulation emerged in the first place, which actors contributed to that emergence, and the patterns of interaction between RECs, the RES, and other regulatory actors, to say nothing of what the day-to-day regulatory practice of RECs looks like. What constitutes ethics review in the practices of RECs, particularly as they become more institutionalized and this 'next-generation' regulation is brought to bear on them?

Regulatory theory helps frame these questions. As the historian Laura Stark has documented, ethics committees first emerged because of historical contingency and political manoeuvring by lawyers, policymakers, and legislators in Washington, DC in the mid-1960s. Out of concern for ongoing research scandals, potential legal liability, and governmental regulation, National Institutes of Health $(\mathrm{NIH})$ policymakers enacted a delegated 'satellite regulator' model as an adaptation of the 'group consideration' structure from the NIH Clinical Center's Clinical Research Committee. ${ }^{7}$ In this model, committees of self-regulating medicoscientific peers at local institutions would review protocols submitted by fellow physician-researchers at their institutions and give 'due consideration' to 'pertinent ethical issues'. ${ }^{8}$

In the UK, we saw a follow-on effect from this American creation, with hospitals establishing RECs beginning in the late 1960s as a

6 ibid 808.

7 Laura Stark, Behind Closed Doors: IRBs and the Making of Ethical Research (University of Chicago Press 2012).

8 US Public Health Service, 'Revised Procedure on Clinical Research and Investigation Involving Human Subjects', 1 July 1966 (Department of Health, Education and Welfare 1966). 
pragmatic response from the US Surgeon General's policy. ${ }^{9}$ But growth and development of RECs were incremental and patchy; they were distinctly not in response to research scandals. ${ }^{10}$ Contrary to the US, it was not until the new millennium that statutory regulation was enacted that set legally binding requirements on RECs' form and function-and technically, this was only for CTIMPs. Thus, for much of their history, RECs were unique products of actively designed decentred regulation, ${ }^{11}$ whereby the government shifted authority to and trust in the medical and scientific professions as well as independent regulatory authorities to set the principles and standards for REC operation. However, as we will see, RECs exhibit a unique kind of regulatory design as compared to common understandings of decentred regulation in that the locus of the activity of regulating RECs has been gradually shifting towards the state.

Surveying the history, three rationales appear to have been at play in the aim of creating health research ethics regulation beginning in the 1960 s, both voluntarily from within the profession and top-down from state actors. These were: (1) to protect research participants from potential harm by minimizing the risks exposed to them by the proposed research; (2) to address information asymmetries between researchers and participants by requiring researchers to explain clearly (e.g. through information sheets) what would be involved in the project, including the potential risks and benefits, to allow (healthy) volunteers and patients to make an informed decision about whether to participate in the project; and (3) to broker a compromise between public welfare-attuned politicians and regulators concerned with safety and public trust (not to mention being perceived to act in the public interest), and professional physician-researchers who were concerned with maintaining freedom of science and minimizing the impact of external regulation that might hinder their research (the argument for 'clinical autonomy'). In the early

9 US Public Health Service, 'Memo to the Heads of Institutions Conducting Research with Public Health Service Grants from the Surgeon General', 8 February 1966 (Department of Health, Education and Welfare 1966).

10 Adam Hedgecoe, 'Scandals, Ethics, and Regulatory Change in Biomedical Research' (2017) 42 Science, Technology, \& Human Values 577.

11 Decentred regulation can be defined as 'a shift (and recognition of such a shift) in the locus of the activity of "regulating" from the state to other, multiple, locations, and the adoption on the part of the state of particular strategies of regulation'. See Julia Black, 'Decentring Regulation: Understanding the Role of Regulation and Self-Regulation in a "Post-Regulatory" World' (2001) 54 Current Legal Problems 103, 112. 
age of RECs' creation, a mixture of public and private interests drove regulation in this nascent regulatory space.

However, the historical tracing in Chapter 3 also suggests that regulatory developments in this area have never purely been a matter of 'public' or 'private' interests (or some hybrid mix thereof), though certainly both exist, and the recent legal instantiation of research promotion may signal a surge of private interests, particularly from the research community (including industry). More is occurring in health research regulation than a prolonged war between public welfare and research autonomy, interspersed with battles or scandals. Instead, even from the nascent stage of the REC system's creation and the emergence of regulatory controls on science, there has been an emphasis on social processes and how they shape health research ethics regulation. The historical tracing in Chapter 3 demonstrates that the progression of regulatory controls, both on RECs and of research involving participants, is symptomatic of incremental process rather than action:reaction punctuated by nodal points in regulatory history. Through an anthropology of regulation, one is able to bridge the historical tracing with present understanding and with future outlook; we cannot understand where we are and where we are going with health research regulation unless we understand where we have been. The past, present, and future are inextricably linked in time and place and bonded by processes of gradual change reflected in the actions of various actors.

\subsection{Regulatory Space}

The analytic concept and metaphor of 'regulatory space', first described by legal scholar Leigh Hancher and political scientist Michael Moran, ${ }^{12}$ and already referred to above, provides useful spatial-temporal framing of the processes here. Regulatory space proponents argue that local context and historical configuration (i.e. time and space), as well as institutional dynamics, affect the relevant regulation and influence the practices that happen within the space. ${ }^{13}$ As to the metaphor itself, regulatory space focuses on networks of regulation and mixing of regulators and strategies:

12 Leigh Hancher and Michael Moran, 'Organizing Regulatory Space' in Leigh Hancher and Michael Moran (eds), Capitalism, Culture and Economic Regulation (OUP 1989).

13 See e.g. Colin Scott, 'Analysing Regulatory Space: Fragmented Resources and Institutional Design’ [2001] Public Law 329. 
The 'space' here is conceived of as a cluster of regulatory issues, decisions, or policies (a 'regulatory arena') that involves the interplay and competition between various interests. Regulatory authority is widely shared between private and public actors (therefore making the distinction largely meaningless), and regulatory approaches are shaped by location, timing, and history. [...] In the world of regulatory space, as in the world of regulatory networks, the idea of 'capture' makes only limited sense; regulatory authority is inherently shared, and private interests are driven to, or accept, playing legitimate roles in the regulation of themselves, of industry sectors (through associations), and of wider society. ${ }^{14}$

The legal scholar Colin Scott argues that regulatory space speaks to the 'resources relevant to holding of regulatory power and exercising of capacities [that] are dispersed or fragmented'; the resources 'are not restricted to formal, state authority derived from legislation or contracts, but also include information, wealth and organisational capacities'.15 Moreover, 'the possession of these resources is fragmented among state bodies, and between state and non-state bodies'. ${ }^{16}$ Scott elaborates:

Put another way, capacities derived from possession of key resources are not necessarily exercised hierarchically within the regulatory space, regulator over regulatee. We recognise the presence within the space not just of regulators and regulatees, but of other interested organizations, state and non-state, possessing resources to a variable degree. Relations can be characterised as complex, dynamic and horizontal, involving negotiated interdependence. This re-conceptualisation of regulatory processes is important in understanding the limits of law within regulation. The dispersed nature of resources between organisations in the same regulatory space means regulators lack a monopoly both over formal and informal authority. This observation draws our attention to the need to conceive of strategies of regulation as consisting of a wide range of negotiated processes, of which rule formation and enforcement are but two. ${ }^{17}$

Further elucidation of the regulatory space is provided by the legal and regulatory studies scholar Julia Black, who suggests that three principal regulatory functions can be mapped across a range of actual or potential regulators - standard setting, monitoring, and enforcement-and a wide variety of institutional actors can be 'enrolled' to carry out, alone

\footnotetext{
14 Hancher and Moran (n 12) 64-5.

15 Scott (n 13) 330.

16 ibid.

17 ibid.
} 
or in collaboration, one or more of these regulatory functions. ${ }^{18}$ Legal scholar Scott Burris and colleagues extend this concept with discussion of polycentric, or 'nodal' character of, contemporary governance, which 'is an elaboration of contemporary network theory that explains how a variety of actors operating within social systems interact along networks to govern the systems they inhabit'. ${ }^{19}$ They posit that institutions (which I would broaden to 'actors') are substantially comprised in nodes, having a set of technologies, mentalities, and resources that mobilize the knowledge and capacity of members to manage the course of events: 'Networks are a prime means through which nodes exert influence.' ${ }^{20}$ Burris finds that there are a number of nodes that do or could help regulators (including ethics committees) regulate how researchers treat research participants. This can range from medical journals to professional organizations to courts to ethicists, all of whom can act as 'norm entrepreneurs' in formulating and disseminating new standards. ${ }^{21}$

The concept of regulatory space, along with insights from polycentric contemporary governance, helps us understand why the current regulation of health research involving human participants is less a matter of public authorities versus private interests. Indeed, the underlying institutionalist framework of research ethics review by dispersed expert ethics committees and pluralist organizational involvement was established already by the 1970s, and this was in large part due to a conscious effort by the state to delegate much of the decision-making authority to private interests in the form of the RCP and other non-state actors.

Interestingly, then, what appears to exist in the UK, at least in the particular space of health research ethics as it pertains to RECs, is a shifting of the locus of regulating towards the state, with more 'centred' or truly polycentric regulation. State actors such as the NHS (via Trusts, Foundation Trusts, and Health Boards and the R\&D offices within them), the Department of Health and Social Care (and their equivalents in the devolved administrations), and the HRA assert much firmer control with

18 Julia Black, 'Enrolling Actors in Regulatory Systems: Examples from UK Financial Services' [2003] Public Law 63. As I argue below, however, the enforcement function has limited application to RECs.

19 Scott Burris and others, 'Nodal Governance' (2005) 30 Australian Journal of Legal Philosophy 30, 33.

20 ibid.

21 Scott Burris, 'Regulatory Innovation in the Governance of Human Subjects Research: A Cautionary Tale and Some Modest Proposals' (2008) 2 Regulation \& Governance 65, 71. 
rules- and principles-driven regulation (e.g. the Clinical Trials Regulations 2004, Care Act 2014, UK Policy Framework, GAfREC, REC SOPs) that both seek to streamline ethics review processes and also remove a degree of autonomy (but not 'independence', they stress) from RECs.

But the state is not the sole controlling entity, of course. It is situated next to the long-standing and previously dominant presence of non-state regulatory actors and sources of authority such as researchers and physicians, industry (e.g. pharmaceutical companies), organizations within the medical and scientific profession (e.g. RCP), and new(er) organizations explicitly promoting a pro-research agenda (e.g. AMS). Unlike standard accounts of decentred regulation, then, here we see that the state has only recently asserted itself into the mix of regulatory actors. Not unusually, each of these actors can exert cross-competing demands and the polycentric nature of the space exhibits potentially cacophonous forms of standard setting, monitoring, and enforcement. Put another way, while the state has recently asserted itself and the HRA has emerged as a central regulatory actor, one can today delineate multiple actors (or 'nodes') that populate the health research regulatory space in the area of research ethics, including:

- RECs;

- research sponsors and institutions;

- NHS (e.g. Health Boards, Trusts, Foundation Trusts);

- Department of Health and Social Care/devolved administration equivalents;

- HRA/devolved administration equivalents (including the RES);

- UKECA;

- MHRA;

- regulatory licensing authorities (e.g. HFEA, HTA);

- regulatory advisory committees (Confidentiality Advisory Group, Public Benefit and Privacy Panel for Health and Social Care; Administration of Radioactive Substances Advisory Committee);

- industry;

- Data Monitoring Committees;

- funders (e.g. Wellcome Trust; MRC);

- courts of law (through litigation and court decisions);

- professional organizations (e.g. RCP, British Medical Association, World Medical Association);

- interest groups (e.g. AMS);

- research colleagues;

- professional ethicists; 
- academic journals;

- news media and journalists;

- research participants; and

- the broader public/civil society.

Clearly, many actors (or 'nodes') populate this regulatory space, which, it must be stressed, merely covers one discrete area: regulation of the ethics of health research involving human participants. Indeed, some argue that in health research the regulatory space is not unitary but in fact comprised of 'a multiplicity of spaces ostensibly engaged in the same endeavour but with little means to learn lessons between them'. ${ }^{22}$ How, then, can we put these nodes under the analytic microscope and make sense of this space or these spaces?

Law is important to consider here, and it is worth highlighting that in the institutionalist and polycentric theory of regulation, law is facilitative rather than prohibitive, 'emphasising non-legal organisational and systemic dynamics as crucial to regulatory objectives', and helping 'to structure the interactions between regulatory participants rather than directly to shape the substance of the regulatory issue'. ${ }^{23}$ Yet law can also police the boundaries of the regulatory space where actors interact, and may be limited in what it can achieve, or holds itself out to achieve. As Colin Scott observes:

[L]aw is more marginal to actions within the regulatory space than lawyers might assume. That political systems seek to use law instrumentally for regulatory purposes does not give law the pre-eminence in ordering society which some argue it had when adjudication was a central form of governance in an earlier period. Indeed, the argument that law is increasingly used to co-ordinate 'pre-existing relationships of power' is at odds with the dominant, but symbolic conception of law as being exercised hierarchically. ${ }^{24}$

So, even if we find, for example, that the Care Act 2014 has bestowed formal legal authority on the HRA to regulate RECs (directly in England and indirectly in the three other nations) and that the HRA has a duty to promote the coordination and standardization of practice in the UK relating to the regulation of health and social care research, as well as a duty to cooperate with each devolved authority in the exercise of their

22 Graeme Laurie, 'Liminality and the Limits of Law in Health Research Regulation: What Are We Missing in the Spaces In-Between?' (2017) 25 Medical Law Review 47, 50.

23 Morgan and Yeung (n 2) 76.

24 Scott (n 13) 334. 
respective functions relating to the regulation of assessments of the ethics of health and social care research, this does not mean that the HRA necessarily possesses actual (read: in practice) regulatory authority over health research. What it means is that the HRA has ultimate (legal) authority, but this is not equivalent to saying that it can or does dictate what happens on the ground or within the regulatory space(s). Things might 'work well', but not in ways that the HRA foresees or would necessarily sanction. The insight from Scott about the limits of law tells us that 'authority' can take many forms, legal and extra-legal, depending on how it is defined, who wields it, when, and in what ways, and who in return is impacted by it. Scott's insight draws attention to the problems inherent in a law-centric research approach. We must be open to the possibility that authority may be wielded in myriad ways and at different times by RECs and other regulatory actors, such as R\&D offices, researchers, and sponsors, who possess key resources of information and organization even if they are not sanctioned with these resources by law.

Thus, we see that the value of regulatory space as an analytic concept is its usefulness in demarking the range of actors and processes in health research, and for 'drawing in perspectives which question the capacities of instrumental law and regulation, and envisage greater reflexivity or responsiveness in systems characterised variously as post-bureaucratic or post-interventionist'. ${ }^{25}$ As Scott writes, '[b]efore we conclude that all key resources are possessed by a single regulatory agency, we ask first whether those resources are in fact dispersed through a more fragmented pattern'. ${ }^{26}$ Lastly, an openness to surprise is warranted when applying a nodal analysis of the regulatory space in this context. For Burris:

The positive potential of a nodal [analytic] view is clear: when the available regulators are identified and their capacities assessed, 'unregulated' activities can be revealed as highly regulated, or potentially so. In the case of human subjects regulation, a diversity of regulators may be creating problems of over-regulation, over-punishment, and over-deterrence. ${ }^{27}$

Ongoing or further recourse to the law as a means of achieving a robust health research regime may, upon analysis, not be appropriate.

It bears noting that some commentators consider a drawback to the regulatory space metaphor to be its difficulties in 'accounting for the

\footnotetext{
ibid 352.

ibid.

27 Burris (n 21) 71.
} 
boundaries of regulatory spaces and in explaining the different dimensions that characterize the "topology" of the space-notably: the relative power of the different actors; the distribution of resource dependence relevant to the space; and the nature of the communication flows between actors' ${ }^{28}$ As will be argued, this, in fact, is where liminality adds key support to the sensitizing concept of regulatory space, especially in better understanding the spaces in-between boundaries. Additionally, an anthropology of regulation rounds out the call for richer characterization of the 'topology' of the space by paying close empirical attention to the dynamics of interaction between actors and how resources are distributed. It complements socio-legal research approaches by investigating the extra-legal elements of social practices from the inside out and paying attention to the processual nature of regulation. Engaging in anthropological investigation of regulation accounts for a deeply contextual understanding of the behaviours and experiences of actors who intentionally intervene in the activities of a target population (i.e. regulators), as well as those actors whose activities have been regulated (i.e. regulatees).

\subsection{Regulatory Approaches: Risk-Based and Proportionate Regulation}

If regulatory space serves as a useful frame to make sense of the range of nodes that share regulatory authority of a given activity, what can be said of the structures, techniques, and strategies deployed by regulatory actors to accomplish their tasks? Risk assessment and management are classic modi operandi of regulators. Baldwin and colleagues observe that 'regulation can be seen as being inherently about the control of risks'. ${ }^{29}$ Recent changes in health research regulation described in earlier chapters suggest a pronounced move towards this risk-focused approach, which also accords with the UK's Hampton Review in 2005 that recommended all UK regulators operate a risk-based system, ${ }^{30}$ and the statutory Regulators' Code, which requires UK regulators to 'base their regulatory activities on risk' and 'choose proportionate approaches to those they regulate'. ${ }^{31}$

28 Robert Baldwin and others, Understanding Regulation: Theory, Strategy, and Practice (2nd edn, OUP 2012) 65.

29 ibid 83.

30 Philip Hampton, Reducing Administrative Burdens: Effective Inspection and Enforcement (HM Treasury 2005).

31 Department for Business, Innovation and Skills, Regulators' Code (UK Government 2014). 
Risk, a pervasive theme in contemporary societies, ${ }^{32}$ can be defined simply as an 'adverse event that may occur in the future'. ${ }^{33}$ The CIOMS Guidelines define risk more specifically to the human research context as 'an estimate of two factors: first, how likely it is that a participant will experience a physical, psychological, social or other harm; and second, the magnitude or significance of the harm' ${ }^{34}$

Risk-based regulation is defined as 'the prioritizing of regulatory actions in accordance with an assessment of the risks that parties will present to the regulatory body's achieving its objectives'. ${ }^{35}$ Surveying the literature, one finds that it generally contains the following key elements (Box 4.1). ${ }^{36}$

Throughout their history, RECs have been charged with assessing, or weighing a favourable 'balancing' of, the harms (i.e. the adverse events) and benefits of a given research project, or phrased another way, risks against the probability of benefit. As the GAfREC state: 'The committee has to be assured that any anticipated risks, burdens or intrusions will be minimised for the people taking part in the research and are justified by the expected benefits for the participants or for science and society.' 37 Elsewhere, it states that 'RECs must be assured about the planned ethical conduct and anticipated risks and benefits of any proposed research' ${ }^{38}$ At least on paper, there would appear to be two general levels of risk in the assessments undertaken by RECs: minimal risk and greater than minimal risk. ${ }^{39}$ For their part, researchers are expected to prepare descriptions of risks and intended benefits for REC members as part of their application,

32 Iain Wilkinson, Risk, Vulnerability and Everyday Life (Routledge 2010).

33 Robert Baldwin and Julia Black, 'Driving Priorities in Risk-Based Regulation: What's the Problem?' (2016) 43 Journal of Law and Society 565, 566.

34 Council for International Organizations of Medical Sciences, International Ethical Guidelines for Health-Related Research Involving Humans (Council for International Organizations of Medical Sciences 2016), Guideline 4, Commentary.

35 Baldwin and others (n 28) 281.

36 Adapted from Baldwin and others (n 28) 281-90 and Gregory Bounds, 'Challenges to Designing Regulatory Policy Frameworks to Manage Risks' in OECD (ed), Risk and Regulatory Policy: Improving the Governance of Risk (OECD 2010).

37 GAfREC para 1.2.2.

38 ibid para 3.2.15.

39 See Annette Rid, 'Rethinking Risk-Benefit Evaluations in Biomedical Research' in Daniel Strech and Marcel Mertz (eds), Ethics and Governance of Biomedical Research (Springer 2016) 153. 


\section{BOX 4.1. ELEMENTS OF RISK-BASED REGULATION}

1. There are three sequential phases in the regulatory approach: (1) assessment (framing and forecasting the probability/possibility and consequences of identified hazards); (2) management (designing and implementing actions and remedies to address risks through a consideration of potential risk treatments and selection of the most appropriate); and (3) review (decisionmaking processes are transparent and open to revision in light of new information);

2. The regulator's aim is to control relevant risks rather (or more) than achieving compliance with sets of rules;

3. Once assessed, a range of responses can be applied to manage the risks, such as risk avoidance, risk reduction, risk retention, and risk transfer;

4. There is clear identification of risks that the regulated organizations (i.e. researchers and their projects) may present to the achieving of the regulator's objectives;

5. There is a comprehensive system for assessing such risks and scoring these in either a quantitative or qualitative manner, underpinned by scientific evidence and a robust decision methodology;

6. There is a linkage of risk scoring mechanism/risk evaluation with resource allocation (e.g. more resources to regulate the higher risk organization or activity);

7. There is recognition that risk tolerance and use of a risk-based framework is more political art than pure technical application; and

8. The risks that the regulator is concerned with may not align with the risks on which regulatees (i.e. researchers) are focused.

and they are expected to discuss them with research participants as part of the consent process as well. Together, the risk-benefit calculus is said to operationalize all three of the 'classic' research ethics principles of beneficence, respect for persons, and justice. ${ }^{40}$

Assessing the elements outlined in Box 4.1 and turning our attention to the context of ethics review, we can speculate that RECs most often engage in risk management techniques of risk reduction (e.g. setting conditions on the research project for it to be ethically acceptable) and risk avoidance (e.g. prohibiting certain research projects or activities within them by not granting a favourable opinion).

Further and relatedly, we can surmise that risk-based regulation is linked with notions of 'proportionate' regulation. In law and regulation, proportionality connects 'the exercise of legal power with doctrines and

40 Robert Levine, Ethics and Regulation of Clinical Research (2nd edn, Yale University Press 1988) 38. 
ideas of reason, fairness, fittingness, and order circulating within broader political and indeed cultural discourse' ${ }^{41}$ As the legal scholar and bioethicist Michelle Meyer notes, there has been 'a global trend toward "risk-proportionate" regulation of [human subjects research]' [...] It aims for two politically unassailable goals - the safety and welfare of research participants and the efficient use of scarce resources-and wraps these goals in the seemingly unobjectionable language of "proportionality"" .42 An OECD report from 2010 observes that '[a] risk-based approach to regulation explicitly acknowledges that the government cannot regulate all risks and that regulatory action, when taken, should be proportionate, targeted and based on an assessment of the nature and magnitude of the risks and of the likelihood that regulation will be successful in achieving its aims'. ${ }^{43}$ It finds that for central regulators (in this case, the HRA for example): 'A significant objective of incorporating a better treatment of risk in regulatory management is to improve regulatory design and administration, to reduce the fiscal costs of administering regulation and minimise the burden that regulation imposes on business and the community.' 44 This language accords with the UK's Regulators' Code, which states that: 'Regulators should carry out their activities in a way that supports those they regulate to comply and grow', which means that, among other things, they 'should avoid imposing unnecessary regulatory burdens through their regulatory activities' and 'should consider how they might support or enable economic growth for compliant businesses and other regulated entities [...]'. ${ }^{45}$

For RECs specifically, an early shift towards risk-proportionate regulation can be traced to the Lord Warner Report from 2005 (discussed in Chapter 3), which recommended proportionate ethics review such that '[ $\mathrm{t}$ ]he remit of NHS RECs should not include surveys or other nonresearch activity if they present no material ethical issues for human participants'. ${ }^{46}$ COREC's response publication in 2006, Building on

41 Nicola Lacey, 'The Metaphor of Proportionality' (2016) 43 Journal of Law and Society 27, 35.

42 Michelle Meyer, 'Regulating the Production of Knowledge: Research Risk-Benefit Analysis and the Heterogeneity Problem' (2013) 65 Administrative Law Review 237, 294-5.

43 Bounds (n 36) 16.

44 ibid 26.

45 Department for Business, Innovation and Skills, Regulators' Code (UK Government 2014) paras 1-1.2.

46 Lord Warner Report 15. 
Improvement, acknowledged that the Lord Warner Report sought 'proportionality of review' as a means to streamline the extant regulation, and in response, COREC recommended introducing 'a research ethics service incorporating RECs working in structured networks, where decisions are made as a result of review proportionate to the level of risk provided by the study' ${ }^{47}$ As noted in Chapter 3, in 2010, following the earlier pilot study from 2009 based on the recommendation from the Lord Warner Report, the PRS was introduced across the UK to operationalize a proportionate regulatory approach based on the level of risk a study proposed.

Similarly, the AMS emphasized the need for proportionate regulation in its report from 2011, recommending it as a key principle underpinning health research regulation (indeed, it was one of the four principles they advocated): "the application of regulation should be both proportionate and symmetrical. A "one-size-fits-all" approach to regulation damages us all. Instead, regulation of health research should be proportionate to the risks and benefits to individuals and society.' 48 Throughout its report, the AMS recommended that an 'ideal' health research regulatory system would, among other things, apply regulatory requirements in a way that is proportionate to the potential benefits and harms of the research. Within ethics review, the AMS encouraged NRES (as it then was) to roll out Proportionate Review to all RECs, opining that:

It is particularly important to adopt a proportionate approach to ethics review because of the diversity of research that undergoes this assessment, which includes: questionnaires for staff and patients, minimally interventional studies and clinical trials of new drugs. The benefits of a proportionate approach are recognised in both the US and Canadian ethics review systems ...49

Even after the HRA's creation, the research community has continued to advocate for a turn towards streamlined and proportionate regulation in the hopes of 'increasing value and reducing waste in biomedical research regulation and management' ${ }^{50}$ In an influential article published in The Lancet in 2014, clinical neurologist Rustam Al-Shahi Salman and colleagues (including Janet Wisely, then Chief Executive of the HRA) wrote

47 COREC Report 9.

48 AMS, A New Pathway for the Regulation and Governance of Health Research (Academy of Medical Sciences 2011) 5. Principle 3 from the report is: 'Be proportionate, efficient and coordinated.'

49 ibid 76.

50 Rustam Al-Shahi Salman and others, 'Increasing Value and Reducing Waste in Biomedical Research Regulation and Management' (2014) 383 Lancet 176. 
alarmingly of 'the increasing burden, inconsistency, and complexity of regulation in the past two decades, sometimes out of proportion to the risk of the research'51 that ultimately had led to a 'threat to public health' ${ }^{52}$ Chief among their concerns was that: 'Although the conceivable risks of research vary, regulatory requirements do not seem to have been designed to be proportionate to the extent to which safety of patients is likely to be jeopardised.' 53 In this context, they cited the example of requiring consent for 'low-risk' epidemiological research and biobanking and the application of the EU Clinical Trials Directive to non-commercial trials assessing licensed treatments that have already been adopted in practice. Though they noted examples from the UK of solutions to some sources of waste and inefficiency in regulation of clinical research (e.g. the development of COREC to NRES to the HRA and the latter's strategic plan from 2013), they also noted much more could be done to reduce 'wasteful regulation and management of research'. ${ }^{54}$ As they wrote: 'The main solution to disproportionality is to limit regulation to whatever is essential, both to protect the autonomy and wellbeing of research participants and to be proportionate to the plausible risks posed to them. ${ }^{55}$ The authors did not explain what might comprise 'essential' regulation.

A final example of proportionate regulation is seen in the Care Act 2014, which mandates the HRA to "promote the co-ordination and standardisation of practice in the United Kingdom relating to the regulation of health and social care research; and it must, in doing so, seek to ensure that such regulation is proportionate'. 56 Operationalizing this legal mandate in practice, the UK Policy Framework for Health and Social Care Research 'recognise[s] the value of [...] proportionate application [of recognized ethical standards and models of good practice] to different types of research' 57 and, throughout, emphasizes a proportionate approach, including as a principle for regulators: 'The HRA has a specific role to ensure the following. [...] a. The regulation of health and

51 ibid 177.

52 ibid 183.

53 ibid 178-9.

54 ibid 183.

55 ibid 181.

56 Care Act 2014, s 111(3) (emphasis added).

57 Health Research Authority, 'UK Policy Framework for Health and Social Care Research' (2017) <www.hra.nhs.uk/planning-and-improving-research/ policies-standards-legislation/uk-policy-framework-health-social-care-research/> accessed 17 October 2019, para 5.1. 
social care research is proportionate, so that research that is clearly lower-risk gets processed accordingly.' 58

Based on the foregoing discussion, a question arises as to whether this next-generation health research regulation implements a risk-based and proportionate approach for RECs that fulfils the elements described in Box 4.1. Are RECs' deliberative processes 'informed by an assessment of the probability of harm expected to arise' from a given research project, or if the probability of harm cannot be calculated, do RECs demonstrate 'a rational and transparent consideration of other relevant factors that for want of evidence remain uncertain'?59 This is a critical and empirical question that will be explored in the following chapters. At this stage, it may be beneficial to look at what the UK regulations state.

In short, what the regulations state about risk assessment by RECs is minimal. The REC SOPs provide no detailed guidance on how risk is to be assessed. Somewhat clearer guidance is provided by international regulatory instruments such as the CIOMS Guidelines, ${ }^{60}$ but as the bioethicist Annette Rid points out, 'there is no explicit upper risk limit when informed consent is obtained, provided the net risks to participants are reasonable in relation to the scientific or social value of the research'.61

Risk-proportionate assessment also lacks clarity. The REC SOPs state that: 'The Proportionate Review Service (PRS) provides for proportionate review of research studies raising no material ethical issues, including projects involving straightforward issues which can be identified and managed routinely in accordance with standard research practice and existing guidelines.' ${ }^{2}$ It then proceeds to discuss procedural guidance on how the PRS is to operate. The GAfREC specify that 'REC review is proportionate to the scale and complexity of the research proposed', ${ }^{63}$ neither of which are attributes that necessarily equate to risk, but nevertheless are seen as linked. A Proportionate Review guidance document published by the HRA lists seven categories (i.e. types of research) considered to present no material ethical issues (e.g. research using prospectively collected data or tissue that is anonymous to the

\footnotetext{
58 ibid para 9.19.

59 Bounds (n 36) 16-17.

60 See e.g. Council for International Organizations of Medical Sciences, International Ethical Guidelines for Health-Related Research Involving Humans (Council for International Organizations of Medical Sciences 2016) Guideline 4.

61 Rid, 'Rethinking Risk-Benefit Evaluations' (n 39) 156.

62 REC SOPS para 4.1.

63 GAfREC para 3.2.4.
} 
researcher), followed by an eighth category, which is described as 'Studies which do not fit categories 1-7 but do not have any "Material Ethical Issues", According to the HRA, these categories prima facie raise no material ethical issues because they 'have minimal risk, burden or intrusion for research participants'.64

Such is how the ethics review system is currently designed for the purposes of assessing risk. Detailed regulatory guidance is lacking, which can raise conceptual and practical challenges. Rid argues that 'frameworks for risk-benefit evaluations of biomedical research remain surprisingly vague', 65 that they 'arguably place too much emphasis on informed consent as a condition of acceptable net risk to participants', ${ }^{66}$ and that the 'documented variation and inconsistency of risk judgments between RECs' ${ }^{67}$ raises concerns about both over- and under-protection of participants from risks, not to mention possible stifling of 'valuable research for overall marginal gains in subject protection'. ${ }^{68}$ In the following chapters, we will consider the extent to which RECs engage in risk-based regulation in practice, and examine how RECs (and the HRA) address the conceptual and practical challenges raised by the lack of clarity surrounding risk assessment.

So far in this chapter, I have argued that sensitizing concepts from regulatory theory, namely regulatory space and risk-based regulation, along with its related concept of proportionality, help us understand why regulation emerged in this space and the different array of actors who partake in regulating health research. However, regulatory theory has its limitations. On its own, it cannot validate whether models (or propositions) hold up in reality; regulatory theory can be highly abstracted and pay too little attention to the 'human' roles in regulatory practice.

We have learned from an ethnographic study of the UK Stem Cell Bank $^{69}$ that instantiated regulation brings nuanced insight into how

64 Health Research Authority, 'Proportionate Review: Information and Guidance for Applicants' <www.hra.nhs.uk/documents/1022/proportionate-reviewinformation-guidance-document.pdf $>$ accessed 17 October 2019.

65 Rid, 'Rethinking Risk-Benefit Evaluations' (n 39). See also Annette Rid and David Wendler, 'Risk-Benefit Assessment in Medical Research: Critical Review and Open Questions' (2010) 9 Law, Probability \& Risk 151; Annette Rid, 'How Should We Regulate Risk in Biomedical Research? An Ethical Analysis of Recent Policy Proposals and Initiatives' (2014) 117 Health Policy 409.

66 Rid, 'Rethinking Risk-Benefit Evaluations' (n 39) 160.

67 ibid 156.

68 ibid.

69 Stephens and others (n 4). 
regulation is actually done on the ground, and what it means to be a regulatee who-it turns out-has more of a regulatory role than theory or law might suggest. Other behaviours and experiences of actors may be missing from law and theory that require a fresh perspective and a new lens. In the following sections, first, I unpack the methodological contribution of anthropology of regulation; then, I argue that liminality is a critical component to anthropology of regulation and a strong response to the need to fill in the knowledge gaps of process and transformation in regulation.

\section{ANTHROPOLOGY OF REGULATION}

This book presents an empirical study of the form and function of regulation, and of the behaviours and experiences of those that impact and are impacted by it. Here, I want to make the claim that a novel methodology is required to drive this study forward in a comprehensive way. The rationale behind anthropology of regulation can be summed up by paraphrasing a well-known quote from the socio-legal scholar Lawrence Friedman: ${ }^{70}$ regulation is a massive vital presence in the world; it is too important to be left to regulators alone-or even to the realm of pure thought. Anthropology of regulation is a methodology grounded in interdisciplinary dialogue and mixed research methods. It sits neither fully within anthropology nor within law or regulatory studies; it is a mode of enquiry in its own right within the broader social science tradition. It is a study of the nature of regulation and of the behaviours and experiences of actors within a given regulatory space (or spaces), and explores ways in which these actors are affected by regulation and in turn how these actors affect regulation.

Anthropology of regulation contributes to the fields of legal anthropology (also known as anthropology of law) and socio-legal studies. Legal anthropology is a similar field, of course, as it aims to understand the nature of law and how it is integral to culture, and likewise how culture is integral to law; in other words, it explores how law is a window into the nature of culture itself. Socio-legal studies (and its disciplinary cousin, legal sociology) employ 'various empirical methods to study

70 Lawrence Friedman, 'The Law and Society Movement' (1986) 38 Stanford Law Review 763, 780. 
what is legal about legal processes, legal institutions and legal behaviour'. ${ }^{71}$ It draws attention to the interfacing social context within which law exists, and concerns itself with the empirical study of law as a set of social practices or as an aspect of a field of social experience. ${ }^{72}$

The limitation of legal anthropology and socio-legal studies is that they tend to take law and legalities as the primary foci of investigation. As the above discussion of regulatory space elucidates, in making sense of the form and function of regulation, law fundamentally provides boundaries around space(s). Or, as the legal scholar and political scientist Austin Sarat and colleagues put it: 'In its basic operation, law attempts to create, police, and occasionally transgress social, spatial and temporal boundaries. [...] Within law's spatio-temporal grid, complex classifications are established, creating boundaries that define individuals, communities, acts and norms ...' ${ }^{73}$ I have argued earlier in this chapter that law's role within the regulatory space is limited; fundamentally, a focus on law alone would inadequately answer research questions that examine not the logic of boundaries, but rather the logic (or illogic) of processes and regulatory spaces. Moreover, the regulatory spaces with which I am concerned-being those occupied by RECs that are explicitly focused on ethics and not law-require an approach to their study that does not presume law is the central object of attention. This said, anthropology of regulation does not appear out of thin air; in at least three ways, it builds on and complements the work of different strands of methodology from legal anthropology and socio-legal studies.

First, scholars have undertaken ground-breaking observational studies of human behaviour in the context of regulatory compliance or regulatory enforcement by a public agency or official. ${ }^{74}$ To some extent, anthropology of regulation owes its allegiance to these pioneering observational

71 Reza Banakar and Max Travers, Theory and Method in Socio-Legal Research (Hart Publishing 2005) Introduction.

72 Roger Cotterrell, 'Sociology of Law' in David Clark (ed), Encyclopedia of Law and Society: American and Global Perspectives (SAGE 2007).

73 Austin Sarat and others, 'The Concept of Boundaries in the Practices and Products of Sociolegal Scholarship: An Introduction' in Austin Sarat and others (eds), Crossing Boundaries: Traditions and Transformations in Law and Society Research (Northwestern University Press 1998) 3-4.

74 See e.g. Keith Hawkins, Environment and Enforcement: Regulation and the Social Definition of Pollution (OUP 1984); Bridget Hutter, Compliance: Regulation and Environment (OUP 1997); Clare Hall and others, Telecommunications Regulation: Culture, Chaos and Interdependence Inside the Regulatory Process (Routledge 1999); Garry Gray, 'The Regulation of Corporate Violations: 
(and typically ethnographic) studies. However, to my knowledge, none of these studies have investigated non- or semi-public regulatory bodies such as RECs. Nor have these studies attempted to branch out from compliance and enforcement reflected in command-and-control regulation so as to analyse both the form and function of non-rules-based regulation and its impact on regulators and regulatees. This book explores risk-based approaches and ethical reflection and governance rather than rules-based compliance or enforcement. In the world of RECs, there is limited 'stick-beating'; at worst, a research project is not approved by the REC and thus cannot commence, or the REC revokes its ethics approval following a material ethical breach. The focus of anthropology of regulation, and specifically my research, is different. As I discuss further below, anthropology of regulation builds on these empirical regulatory studies through its theoretical underpinning of liminality, which draws attention to the processual nature of regulation and the importance of human experience during periods of uncertainty and transition. Anthropology of regulation also extends this work as it does not seek merely to identify, document, and understand observed regulatory practices. Through its multi-method approach, it also seeks to provide larger theoretical and normative insight into regulatory processes within a given space and within a given society. That is, it aims to prescribe and evaluate the desirability of different regulatory strategies and styles.

Second, Sally Falk Moore's ground-breaking 'sociological study of reglementation', which she defines as 'the study of the way partial orders and partial controls operate in social contexts' ${ }^{75}$ provides foundational support to anthropology of regulation. As a legal anthropologist, Moore, too, desires a qualitative exploration of social processes and order that occur beyond state-based law, considering 'reglementation' as covering both 'government law and non-governmental sites of rule-making and/or rule-enforcing'. ${ }^{76}$ Moore recognizes that 'reglementary control can be only temporary, incomplete, and its consequences not fully predictable' ${ }^{77}$ Nevertheless, Moore quite clearly bases her approach on rules, coded as elements of order and control, which consequently envelops regulation within a relatively narrow paradigm. I have made clear that my empirical study concerns itself with regulation, which is much broader than law,

Punishment, Compliance, and the Blurring of Responsibility' (2006) 46 British Journal of Criminology 875.

75 Sally Falk Moore, Law as Process: An Anthropological Approach (Routledge \& Kegan Paul 1978) 30.

76 ibid 18.

77 ibid 30 . 
even if law is defined as including non-state forms of normative ordering. And, to reiterate, unlike Moore, I believe regulation must include not only rules, but also principles, mechanisms, strategies, or activities promulgated by state or non-state actors that either affect behaviour as an incidental effect or are designed to steer behaviour in a socially, politically, and/or economically desirable way. This notion of regulation privileges neither the state nor rules. It does, however, accept and incorporate Moore's message that a researcher should take 'into account that there is a constant struggle between deliberate rule-making and planning, and other more untameable activities and processes at work in the social aggregate, [which] should be inspected together' ${ }^{78}$

Third, institutionalism (e.g. sociological institutionalism, historical institutionalism, political institutionalism) is an approach that examines, often through empirical methods, how actions and decisions by individual actors may be influenced (or structurally determined) by higherlevel institutional factors and contexts. ${ }^{79}$ While anthropology of regulation certainly acknowledges that social processes shape regulation (and indeed it is influenced by the institutionalist approach of regulatory space), it does not presume that institutions and institutional frameworks influence or constrain decision-making. More importantly, it does not focus its analysis on the structural level of institutions (e.g. laws, the HRA, RECs) to explain processes and outcomes at a lower level (e.g. decision-making by a REC or individual REC members). It does not ask how institutions affect the behaviour of individuals, nor how individual behaviour affects the evolution of institutions. Rather, anthropology of regulation engages in investigation of regulation itself as both an ontological and functional concern. It examines the ways in which regulatory actors affect and are affected by processes of regulation, which in turn sheds light on regulation as a social form. The unique contribution of anthropology of regulation is that it focuses on the behaviours and experiences of regulatory actors within a space (or spaces) and the ways in which they themselves are affected by regulation, but it does so by scaling up of the units of analysis, from the individual level to the social level and drawing insights from empirical research to accomplish what the regulatory space metaphor seeks to do: examine 'how the actions and intentions of regulatory actors are embedded in larger systems and

78 ibid 29.

79 Edwin Amenta and Kelly Ramsey, 'Institutional Theory' in Kevin Leicht and J Craig Jenkins (eds), The Handbook of Politics: State and Civil Society in Global Perspective (Springer 2010) 15. 
institutional dynamics' ${ }^{80}$ And indeed, the research questions in this study explore and explain - through documentary research comprised of historical tracing and present-day regulatory analysis that explicates the internal constitution of regulation, as well as through observation and interviews - the experiences and behaviours of specific individual actors (i.e. units or nodes) in the health research regulatory space governing the ethics of health research involving participants, namely RECs and their managing regulators.

In sum, there are limits to law-based or even rules-based methodological approaches. Anthropology of regulation allows me to investigate both the nature of regulation as a social form (an ontological concern) and what regulation does to actors and what actors do to regulation (a functional and experiential concern). In so doing, it permits recognition of the limits of regulation, taking up Moore's apt message (at least through the prism of rules) that we should be cognizant of 'social processes which operate outside the rules, or which cause people to use rules, or abandon them, bend them, reinterpret them, side-step them, or replace them' ${ }^{81}$ Regulatory theory is necessary to help provide potential explanatory background; empirical research is equally necessary to help provide understanding of everyday practice. In essence, anthropology of regulation allows us to bring theory and practice meaningfully together.

Anthropology of regulation consists of theoretical underpinnings drawn from regulatory and anthropological theory and is grounded in a trinity of empirical research methods to provide 'a confluence of evidence that breeds credibility'. ${ }^{82}$ The approach is interpretivist rather than positivist: it considers people as products of their environment and as those who construct the environment through their understandings of it. The focus is on subjective understandings: the 'inner worlds' of people and their understanding of the world. ${ }^{83}$ It does not seek to produce 'objective' findings about human activities (of which regulation is part) precisely because it rejects that such a position is possible. Documentary research uses interpretive methods to examine sources of regulation to

\footnotetext{
$80 \quad$ Morgan and Yeung (n 2) 59.

81 Moore (n 75) 4.

82 Elliot Eisner, The Enlightened Eye: Qualitative Inquiry and the Enhancement of Educational Practice (Collier Macmillan Canada 1991) 110, quoted in Glenn Bowen, 'Document Analysis as a Qualitative Research Method' (2009) 9 Qualitative Research Journal 27.

83 Lisa Webley, 'Qualitative Approaches to Empirical Legal Research' in Peter Cane and Herbert Kritzer (eds), The Oxford Handbook of Empirical Legal Research (OUP 2010).
} 
determine how regulation has developed and been applied over time. It asks both what the law is on a particular issue and how an activity is regulated and how that regulation has developed over time. It is, in other words, research into regulation, regulatory concepts, regulatory practices, and the symbioses between them. The result of such interpretation is both descriptive analysis (explaining how a segment of regulation fits within the larger regulatory space) and normative evaluation of the processes of regulating an activity. The empirical evidence gathered through observation and interviews adds to our understanding of human behaviours and experiences, and also is analysed qualitatively. While the specifics of the epistemological and ontological positions, as well as the detailed steps in the empirical research, are described in Appendix 1, the claim I wish to make here is that anthropology of regulation's detailed attention to regulatory sources and human behaviours and experiences allows us to take special notice of context-historical, political, legal, economic, social, cultural, organizational-to explain and understand the nature of regulation as well as the experiences of regulatory actors who both regulate and are regulated. While this might, tangentially, touch on understandings of law, legal concepts, and even legal consciousness of actors, ${ }^{84}$ this approach extends socio-legal studies and legal anthropology by fundamentally focusing on that which is regulatory. Box 4.2 summarizes the key elements of anthropology of regulation.

I have mentioned that anthropology of regulation focuses on the processual and is underpinned in part by theory drawn from anthropology. I have not yet discussed the intricacies of anthropological theory and why it serves as a crucial component of the anthropology of regulation. In the following section, I expand on liminality as a key anthropological concept (and as another 'sensitizing concept') that underpins this methodology and is a crucial component of my investigation of RECs and next-generation health research regulation. As I will argue, liminality helps us to understand the processual dimensions of regulation - the passages of actors from one stage to another, to document and understand experiential dynamics in regulatory spaces, and to reconceptualize the nature of health research regulation.

84 For discussion of legal consciousness and the fluidity of legalities as experienced in everyday life, see generally Susan Silbey, 'After Legal Consciousness’ (2005) 1 Annual Review of Law and Social Science 323. 


\section{BOX 4.2. KEY ELEMENTS OF ANTHROPOLOGY OF REGULATION}

1. Definition: the study of the nature of regulation and of the behaviours and experiences of actors within a regulatory space (or spaces), and the ways in which they themselves affect and are affected by processes of regulation.

2. Theoretical underpinnings: informed by theoretical underpinnings from regulatory theory (i.e. regulatory space) and anthropology (i.e. liminality) that together draw attention to the human factors that determine the nature of regulation and how regulators actually work, as well as the connections between regulated objects and the subjects (e.g. humans) connected to them.

3. Methodological approach: empirical research set within an interpretivist tradition that is constructed around a multi-method approach ${ }^{85}$ ('research trinity') of document analysis, interviews, and observations to make sense of the form and function of regulation (i.e. what it is and how it is expressed) and its impact on regulators and regulatees (i.e. how it is experienced).

o Document analysis: qualitative analysis (e.g. content analysis and thematic analysis) of regulatory sources (e.g. texts) covering a particular area that provides context and historical tracing of how regulations developed and have been applied over time. This includes analyses of the relationship between regulations and regulatory actors. The research is a two-part process that first involves locating regulatory sources (historical and current), and then involves interpreting and analysing the sources to make sense of processual developments. The outcome of the analysis can be both descriptive and normative.

o Observations and interviews: evidence of the behaviours and experiences of regulatory actors who both regulate and are regulated gathered through direct observation. The gathered evidence is typically analysed qualitatively (i.e. thematic analysis), which, as with document analysis, can be both descriptive and normative. The observation may be naturalistic or participant-based; the interviews may be unstructured or semi-structured.

4. Goals: (1) to explain and understand the processual nature of regulation and the behaviours and experiences of regulatory actors who both regulate and are regulated (i.e. how they understand their own actions); and (2) to provide larger theoretical and normative insight into regulatory processes within a given space and within a given society.

85 I avoid the term 'ethnographic approach' as ethnography implies a particular set of features, whereas anthropology of regulation's features are broader and may be non-ethnographic, e.g. naturalistic observation for a short period of time. 


\section{LIMINALITY}

\subsection{The Value of Liminality to Anthropology of Regulation}

As defined by Bjørn Thomassen, liminality is an anthropological concept that 'refers to moments or periods of transition during which the normal limits to thought, self-understanding and behaviour are relaxed, opening the way to novelty and imagination, construction and destruction'. 86 Thomassen argues that liminality is a universal concept because 'cultures and human lives cannot exist without moments of transition, and those brief and important spaces where we live through the in-between' ${ }^{87}$ Given its universality, Thomassen argues liminality should be posited as a central concept in the social sciences, akin to 'structure' and 'practice', for it gives meaning and understanding to how humans experience and react to change - and indeed, liminality is foremost based on experience, because to experience something means, etymologically, to go through something. Liminality is thus not so much an explanatory concept as it is a state of affairs: it exists, it happens, and humans 'react to liminal experiences in different ways' ${ }^{88}$ It constantly 'emerges in the in-between of a passage' 89 and through its constant appearance, it helps us understand transition periods and social processes of change. Liminality can apply to individuals, groups, and even societies, and may occur in a single moment, over a period, or across an epoch. Similarly, liminality has a spatial dimension that can relate to specific places or thresholds (e.g. a doorway in a house), areas (e.g. airports, border areas between countries), and countries or larger regions (e.g. ancient Palestine). ${ }^{90}$ Examples of liminal experiences include marriage, baptism, puberty, graduation ceremonies, New Year, natural disasters, and revolutions.

Liminality serves as an integral component of anthropology of regulation and, as further advantage, accords well with regulatory theory. Both regulatory space and liminality affix themselves to the temporal and spatial dynamics of various actors. However, whereas regulatory space affords a metaphysical mapping of the actors involved in the space (or spaces), liminality affords a processual and experiential understanding of those actors and the ways in which they are affected by regulation,

86 Bjørn Thomassen, Liminality and the Modern: Living Through the In-Between (Ashgate 2014) 1.

87 ibid 4.

88 ibid 7.

89 ibid 2.

90 ibid 90-91. 
particularly at moments or periods of transition where uncertainty is paramount. The value of liminality is that it serves as a lens to make sense of the processual nature of health research regulation and RECs (and individuals therein) as key nodes in the health research regulatory space. It shines analytical light on the kinds of potentially transformative activities RECs both perform and experience. It offers perspective on what it means to be a regulator of health research, and also indirectly through my empirical investigation, draws attention to the experiences of researchers and research participants who, individually and collectively, undergo the transformative experience of becoming these embodied actors.

Liminality also supplements the concept of risk-based regulation. Risk-based regulation is about dealing with uncertain futures through the prism of risk identification and management. Liminality often-indeed, usually-occurs when there are moments of change and uncertainty. A lens of liminality therefore helps us both to recognize uncertainties, embrace them to a certain extent, potentially even exploit them, and pay attention to what is required to work through them. Liminality thus has the potential to yield novel insights into the nature of health research and its regulation-and the limits thereof, namely by helping us to uncover alternative paths to governing the behaviour of various actors and enforcing norms across sites of authority in research ethics oversight. It further helps us consider the importance of transition and transformation among critical components of health research.

In what follows, I trace liminality's conceptual evolution.

\subsection{The Conceptual Evolution of Liminality}

Liminality as a concept emerged at the beginning of the 20th century. In 1909-a period marked by progressivism and trust in scientific methods-the anthropologist Arnold van Gennep wrote that upon analysis of 'detailed descriptions and monographs concerning magicoreligious acts' throughout the world, he could 'attempt a classification of these acts, or rites, that would be consistent with the progress of science'. ${ }^{91}$ Van Gennep found that all cultures exhibit ritual behaviour (i.e. ceremonies or rites) to mark the passage of an individual or social group from one status to another. However, van Gennep singled out 'rites

91 Arnold van Gennep, The Rites of Passage (University of Chicago Press 1960 [1909]) Introduction. 
of passage' in his study as he found them to serve as a critical component of the reproduction of social order:

The life of an individual in any society is a series of passages from one age to another and from one occupation to another. [...] The underlying arrangement is always the same. Beneath a multiplicity of forms, either consciously expressed or merely implied, a typical pattern always recurs: the pattern of the rites of passage..$^{92}$

In each of these series of passages, ceremonies are invoked by the society in which individuals are situated to enable them 'to pass from one defined position to another which is equally well defined', ${ }^{93}$ and consequently, these ceremonies share a wide degree of similarity (seen, for instance, in birth, childhood, marriage, and funerals).

Though he did not invoke the noun 'liminality' as such, nor ever define it, van Gennep posited a tripartite conceptual schema of these ceremonial patterns that 'accompany a passage from one situation to another or from one cosmic or social world to another', 94 and selected rites of passage as a special category of transition, which he then subdivided into: (1) the symbolic separation of individuals (or a group) from their existing social position (rites of separation); (2) the transformation of their social status as they pass through an adjacent space (liminal or transition rites); and (3) their spatial and symbolic reincorporation into society (rites of incorporation). Van Gennep clarified that 'although a complete scheme of rites of passage theoretically includes preliminal rites (rites of separation), liminal rites (rites of transition), and postliminal rites (rites of incorporation), in specific instances these types are not always equally important or equally elaborated'. ${ }^{95}$ Indeed, van Gennep reiterated several times in his seminal work that the 'liminal' stage often takes on an autonomy of its own.

Often during the transition (liminal) periods in the rites of passage, van Gennep observed that:

a special language is employed which in some cases includes an entire vocabulary unknown or unusual in the society as a whole [...]. This phenomenon should be considered of the same order as the change of dress,

\footnotetext{
92 ibid 2-3, 191.

93 ibid 3.

94 ibid 10.

95 ibid 11.
} 
mutilations, and special foods (dietary taboos), i.e. as a perfectly normal differentiating procedure. ${ }^{96}$

Van Gennep further found that the passage from one social position to another is associated with a territorial passage, seen for example in the crossing of streets or entrance into a house or moving from one room to another. 'This identification explains why the passage from one group to another is so often ritually expressed by passage under a portal, or by an "opening of the door". 97 This focus on territorial passage draws attention to the passages that research protocols go through as they wend their way through the stages of the research lifecycle, an observation that I will return to in the following chapters.

Liminality has been further developed in recent decades by scholars who apply the concept from various disciplinary perspectives to modern social settings and social theorizing of modernity, be it political revolutions, earthquakes, gambling, or bungee jumping. ${ }^{98}$ Thomassen argues that liminality is omnipresent in modernity, thus completing a circle from what might otherwise seem like a marginal and antiquated anthropological account of status passages in exotic lands to a central conceptual device that helps to capture key features of many moments of modern life. ${ }^{99}$ Scholars increasingly have plumbed the analytic depths of liminality as well. Árpád Szakolczai contends that any rite of passage 'must follow a strictly prescribed sequence, where everybody knows what to do and how' and that 'everything is done under the authority of a master of ceremonies, the practical equivalency of an absolute ruler [...] whose word is Law - though only during a rite, when there is no law' ${ }^{100}$ Other scholars, however, qualify Szakolczai's observation by suggesting liminal experiences need not always be demarcated with an institutionalized transition 'rite' and with identifiable masters of ceremony, ${ }^{101}$ such as in moments of 'spontaneous liminality' which is unforeseen and resulting from crisis. ${ }^{102}$ Yet Szakolczai's contention that there is often an independent actor serving as a master of ceremonies to guide people through

\footnotetext{
96 ibid 169.

97 ibid 192.

98 Thomassen, Liminality and the Modern (n 86); Agnes Horvath and others (eds), Breaking Boundaries: Varieties of Liminality (Berghahn 2015).

99 Thomassen, Liminality and the Modern (n 86).

100 Árpád Szakolczai, 'Liminality and Experience: Structuring Transitory Situations and Transformative Events' in Horvath and others (n 98) 18.

101 Bjørn Thomassen, 'Thinking with Liminality: To the Boundaries of an Anthropological Concept' in Horvath and others (n 98) 39.

102 Laurie (n 22).
} 
rituals, moments, or periods of transition may have some powerful resonance in health research regulatory encounters; it is one I will return to in the following chapters.

For this empirical study, the key relevant and important features of liminality are its focus on processual change and transformation, and the numerous actors that experience uncertainty and transformations as a result of health research and regulation, both of which in turn cause reflection on how regulatory apparatuses structure process and transformation. Liminality also draws attention to authority figures that may guide actors through status passages. The regulatory theory literature notes that significant coordination challenges can arise in getting actors within a regulatory space to operate effectively. Various modes can be devised in response. One such mode is hierarchy, where, often through a legal framework, a top-down arrangement is instituted such that a central control body lays down rules that direct lower-rung institutions within the network. Through the lens of liminality, this is something to consider as existing between the HRA and RECs. For example, the HRA Approval process could be seen as a liminal period in itself. This new procedure was launched in 2016 for researchers and RECs in England, with direct impact on how they do their work (researchers in putting together the application; REC members in changing which aspects they should be reviewing). The HRA instituted HRA Approval with the express purpose of smoothing the regulatory approvals process for researchers. Yet the roll-out was somewhat controversial for REC members, a fair number of whom were, at least in my discussions with them, unfamiliar with the regulatory changes and felt left in the dark from the HRA about how these changes bore upon them. Not uncommonly, REC members expressed concern to me that the HRA had imposed something top-down on them, perhaps for a good reason, but in a way that also created uncertainty and frustration. A second example of a liminal period includes the HRA's gradual move to a paperless system via the HARP - a significant change when one considers the amount of paper that dominates REC operations-which also has caused some controversy among REC members as a fair number consider paper-based documentation crucial to their undertaking of a thorough ethics review.

Another key feature of liminality is the attention drawn to rituals, which reflect the fundamental values of a group of actors. Additionally, a regulatory network coordination mode itself can be based on rituals. Rituals can function as 'structured processes that serve to organize not only the actions taken by network members but the meanings that 
participant individuals or organizations give to events or decisions' ${ }^{103}$ They may be imposed or voluntarily adopted by the network, 'but the essence of ritualistic network coordination is that embedded processes drive forward the collaborations that are found within the network' ${ }^{104}$ For many regulators, the central motivation is to employ ritualistic processes 'in a manner that serves their own organizational interests. Their broad attitude will be that interactions with other agencies can best be seen in terms of their impact on achieving success in rituals. Claims and responses will be processed through embedded procedures and will be structured accordingly.' ${ }^{105}$ From within the literature on regulatory theory, Baldwin and colleagues explain:

In ritualistic cohabitations, processes can be used to allocate institutional roles and to encourage the development of common aims and approaches by ordering experiences, creating shared meanings, building feelings of community, and encouraging trust. They may be used to facilitate the development of discourses that generate bodies of common knowledge, generalized ways of seeing challenges and problems, and authoritative versions of situations and values. The difficulty, however, is that, in the absence of authority, rituals may not suffice to reconcile all interests and perceptions and this may impede the establishing of objectives and an organized regime for delivering on these. Rituals, moreover, can lead to stultification if they are following unthinkingly. ${ }^{106}$

Yet, despite recognition of rituals in regulatory theory, the notion is underexplored both theoretically and empirically. Nora Machado and Tom Burns, two of the few scholars to explore rituals in regulation, explain that 'complex social organizations' (e.g. a state, university, corporation, nuclear system, regulatory agency, large-scale medical system) contain heterogeneous modes of organizing, with each mode containing its own principle, constitutive rules, norms, identity, and so on. ${ }^{107}$ These heterogeneous modes can generate benefits, such as creativity, reflectivity, and innovation, but they also can sometimes contribute to incongruences, tension, and conflict. To mitigate these problems, organizational spacing, mediators, discourses, and rituals can play a key role. Rituals for Machado and Burns are defined as 'a type of patterned or

\footnotetext{
103 Baldwin and others (n 28) 161.

104 ibid.

105 ibid 162.

106 ibid 163.

107 Nora Machado and Tom Burns, 'Complex Social Organization: Multiple Organizing Modes, Structural Incongruence, and Mechanisms of Integration' (1998) 76 Public Administration 355.
} 
institutionalized symbolic action, collectively defined and constituted within a group or organization. It consists of words, gestures, and actions and use of objects and artefacts to express a conception, symbolic meaning, feeling or sentiment within a group or collectivity.' 108 They are "one of the most important devices to define and "re-structure" the experience of situations and events'. ${ }^{109}$ Machado and Burns explain that rituals minimize incongruence and tension in non-discursive and nonrationalized ways; this is seen, for example, in hospital rituals that range from rituals of caring (e.g. fixing pillows, touching the patient, taking temperature, writing down information) to rituals of authority and deference such as medical rounds, consultation, case conferences, and mortality and morbidity conferences. These rituals are embedded to a significant degree in the schedules, procedures, and practices of a hospital: 'Through institutionalized rituals within hospitals, professionals structure their own experiences and the experiences of their clients and avoid or negate considerably incongruent or disequilibrating information and experience.' ${ }^{110}$ As they further elaborate:

Ritual helps to: (a) order the experience in critical situations by creating and re-creating a sense of order in a chaos of experiences, and gives a sense of security through a pattern of predictability (where for example an individual knows what is, has and will be done in such situations); (b) enforce a given meaning in an unclear situation; and (c) strengthen the sense of community that shares knowledge about what is to be done in ambiguous and critical situations. An important characteristic of ritual (and ritualized behaviour) that to a large extent accounts for its effectivity and cultural persistence - is that it enables actors to collectively handle ambiguous and incongruent situations in a non-discursive (i.e. non-verbalizable) way. ${ }^{111}$

We can draw a parallel here to the HRA and the RECs they manage, and in turn, to the interface between RECs and researchers. There are rich linkages between rituals, regulation, and liminality, especially the notions of transition from one stage or threshold to another. Liminality is particularly helpful in adding value to the analytical framing. It demonstrates how rituals and processual developments across time and space in fact play a crucial role in regulatory coordination when we consider the ways in which an activity (e.g. research) may be regulated by a network of regulators (e.g. RECs, MHRA, HRA) through a variety of rituals

\footnotetext{
108 ibid 372.

109 ibid 373.

110 ibid.

111 ibid 373-4 (emphasis in original).
} 
(e.g. the informed consent process, the drafting of a research protocol and ethics review application, the rituals performed by REC members at meetings) that work across numerous thresholds, and which in turn can have a tangible impact on the regulatory actors' behaviour-particularly when those rituals are disrupted by regulatory change. Liminality thus supplements regulatory theory by encouraging us to identify and pay attention to symbolically and practically significant stages or thresholds. And, given the processual nature of regulation and the regulatory spaces that exist within health research, liminality also buttresses anthropology of regulation by providing a lens for understanding human experiences within health research and the roles of regulation within these spaces.

\section{CONCLUSION}

In this chapter, I described the research approach, theoretical underpinnings, and analytical concepts that drive this empirical investigation of RECs and health research regulation. Particular attention was drawn to ideas from regulatory theory and anthropology, namely the metaphor of the regulatory space, risk-based and proportionate regulation, and liminality. I argued that there are limits to what regulatory theory can tell us about 'what is going on', how and why anthropology of regulation complements common socio-legal research approaches, and how it naturally aligns with liminality. Anthropology of regulation draws attention to experience, time, and space(s) that are otherwise often overlooked in analyses (too narrowly) fixated on law as the object of investigation or (too broadly) fixated on social patterns of interaction. I closed this chapter with discussion of the evolution of liminality and its contribution as a sensitizing concept to anthropology of regulation.

Having described the methodological approach, I now turn to present what the empirical research findings tell us about the nature of the interaction between central regulators and RECs in the health research regulatory space, and the functional operations and deliberative processes of RECs in an era of twinned regulatory objectives of participant protection and research promotion. We will see whether the empirical research findings reflect and validate the suggestions supplied in earlier chapters - that RECs engage in risk-based regulation, that health research regulation is increasingly grounded in a principle of proportionality, and that health research regulation is increasingly 'centred' such that the state, especially through the HRA, is exercising growing influence and control. 